\title{
Shareables: An in-flight gift system
}

\author{
Roderick Huijgen \\ Delft University of Technology
}

\section{Shareables: An in-flight gift system}

Shareables is a service concept in which flight attendants collect and distribute personalized gifts for air passengers. The service consists of two parts. The first part entails the collecting and sorting of appropriate gifts by a group of enthusiastic volunteers within the pool of flight attendants. These volunteers buy gifts that they find appropriate for the collection, in their spare time at home or while at a destination. The gifts are collected in a sharing hub that is located at the crew center of the airline's headquarters, which every flight attendant passes through before flying out (Figure 1). They and all other flight attendants can subsequently pick up gifts for their upcoming flight.

For the second part of the service, flight attendants take some of the gifts on-board to distribute them during the flight. The goal of the gifts is to positively influence passengers' emotions and motivations. Since people's emotions change during a flight, different gifts are appropriate for different people at different times (Figure 2). For example, the mood of a bored passenger may be improved by giving her a puzzle, while a sullen child may receive a bubblewrap sheet that he can ravage to attain a state of pleasant anger (see Table 1 for additional examples).

The decisions of both the collection and distribution of gifts is based on the flight attendant's own expertise and experience with passengers, but also guided by reversal-theory knowledge about motivational states and reversals. Gifts are put in different categories according to the emotional and motivational effect they achieve, for instance, "gifts that reverse people to the telic state," or "gifts that increase arousal (in the paratelic state)."

The idea behind the service concept is that passengers like to receive small surprises and personalized attention during a flight experience that is largely standardized. Similarly, flight attendants want to be able to do something extra for passengers who are having a suboptimal flight experience, and enjoy giving a personal touch to the service they provide.

Roderick Huijgen, Department of Industrial Design, Delft University of Technology.

Correspondence concerning this article should be addressed to Roderick Huijgen, Delft University of Technology, Department of Industrial Design, Landbergstraat 15, 2628 CE Delft, The Netherlands E-mail: RGHuijgen@gmail.com
Table 1

Possible on-board gifts based on passenger emotion and state.

\begin{tabular}{lll}
\hline $\begin{array}{l}\text { Passenger } \\
\text { emotion and state }\end{array}$ & Gift strategy & Gift example \\
\hline $\begin{array}{l}\text { Bored (paratelic, } \\
\text { low arousal) }\end{array}$ & $\begin{array}{l}\text { Increase arousal with } \\
\text { an exciting product }\end{array}$ & Thrilling short story \\
\hline $\begin{array}{l}\text { Sullen } \\
\text { (negativistic- } \\
\text { paratelic, low } \\
\text { arousal) }\end{array}$ & $\begin{array}{l}\text { Increase arousal with } \\
\text { a creative, rebellious } \\
\text { product }\end{array}$ & $\begin{array}{l}\text { Booklet with famous } \\
\text { people to draw } \\
\text { moustaches on }\end{array}$ \\
\hline $\begin{array}{l}\text { Bored or sullen } \\
\text { (paratelic, low } \\
\text { arousal) }\end{array}$ & $\begin{array}{l}\text { Reverse to telic by } \\
\text { introducing }\end{array}$ & Rubix cube \\
\hline
\end{tabular}

\section{Design challenge}

This design was part of the author's Master's thesis in Industrial Design Engineering at Delft University (Huijgen, 2014), executed in collaboration with the In-flight Services department of KLM Royal Dutch Airlines. The project focused on designing something that would improve the interaction between flight attendants and (Economy Class) passengers on long-distance flights.

KLM assigns much value to their cabin crew and believes they are an important part of what distinguishes them from the competition. KLM flight attendants are relatively highlyeducated individuals who enjoy personally connecting with passengers. Many of the attendants fly part-time, and also tend to other occupations, some of them in the creative field. KLM has the vision to support the individuality and talent of the flight attendants in their work, to make them and their passengers happier.

Flight attendants face several challenges in having meaningful interactions with passengers. First, the majority of their time and energy is spent on the standard procedures to prepare and serve food and drinks to passengers. Second, although many passengers are potentially interested in personal interaction with the crew, many submerge into a state of cocooning, in which they mentally and physically detach from what is happening in the plane. 

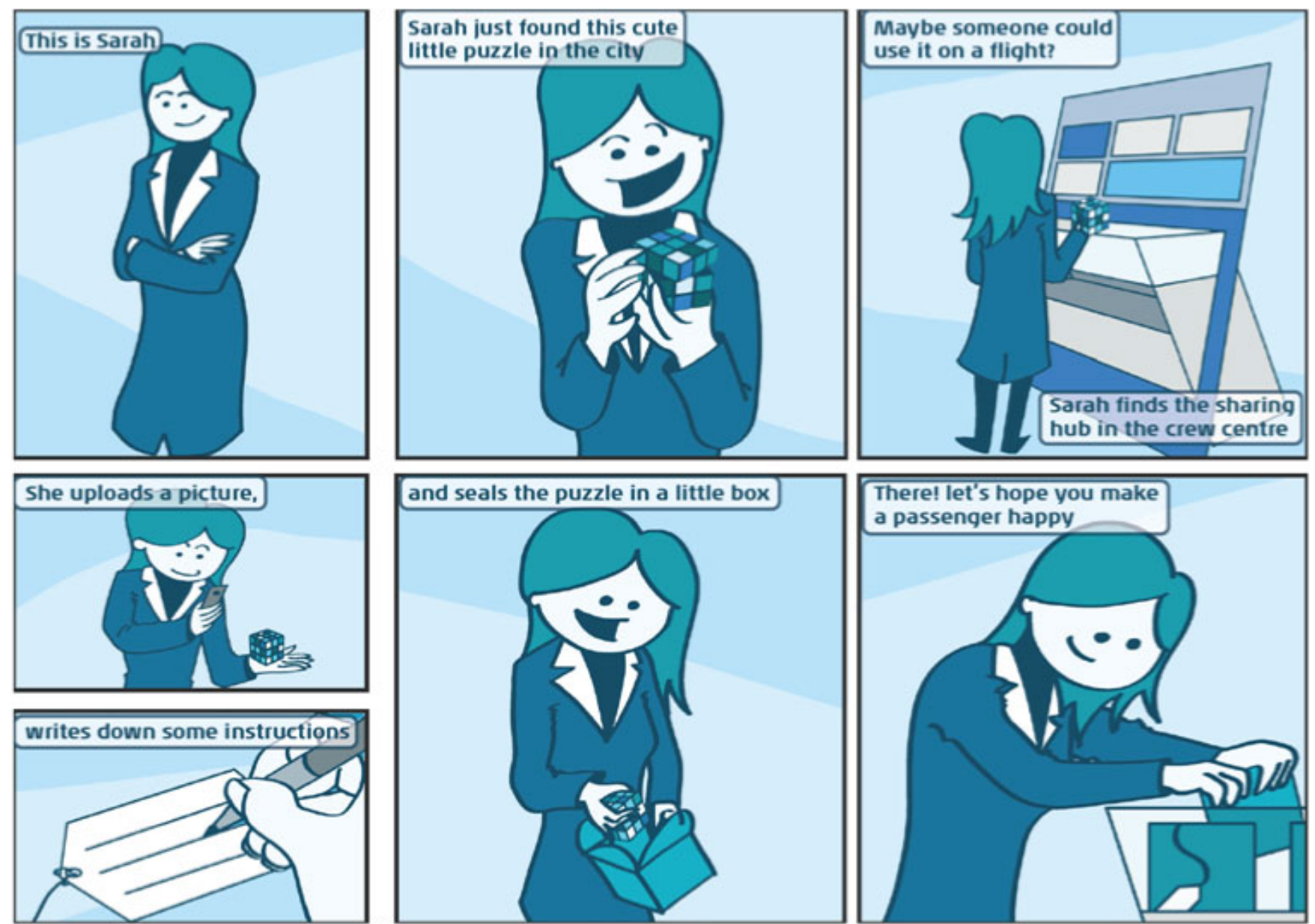

Figure 1. Scenario of the gift-collecting aspect of the Shareables service.

\section{Project approach}

Since the project focused on the interaction between passengers and crew, both groups were investigated in the research phase. A focus group session was organized with six KLM flight attendants of varying ranks and service years, to research their motivations and experiences with passenger interactions. The session was guided by the carousel of feelings tool (see Van Midwoud et al., this issue), through which the moderator made cumulative scenarios based on the input of the participants. This produced the main findings from the perspective of the cabin crew.

The passenger experiences were investigated through an explorative questionnaire that was handed out on-board of an intercontinental flight (12 participants returned their questionnaire). The questionnaires took between 30-120 minutes to fill out, depending on the amount of time the passenger was willing to spend on it. It probed on people's emotions and motivations during various stages of the flight, focusing on the interactions with the cabin crew.

The results of the focus group session and questionnaire were combined, and produced an overview of how crew and passengers felt about and reacted to different in-flight situations. This formed the starting point for the design phase, in which a concept was iteratively designed that aimed to improve crew-passenger interaction overall (instead of focusing on a specific interaction problem). The design phase was structured as an iterative design process (Roozenburg \& Eekels, 1995).

\section{Insights and design implications}

The focus group session revealed that attendants enjoy personal interaction with passengers. Many tried to do a little extra for passengers to make them feel better. For example, attendants remember the passengers' preferred beverage or try to say something in their language, both of which could pleasantly surprise them. Attendants greatly appreciated it if passengers expressed genuine gratitude for their efforts. However, a major obstacle in providing personalized service is the lack of possibilities and time to do so in-flight. Apart from short conversations, there is little that attendants can do on top of the basic service. Secondly, many passengers cocoon during a long flight, which means that they become 

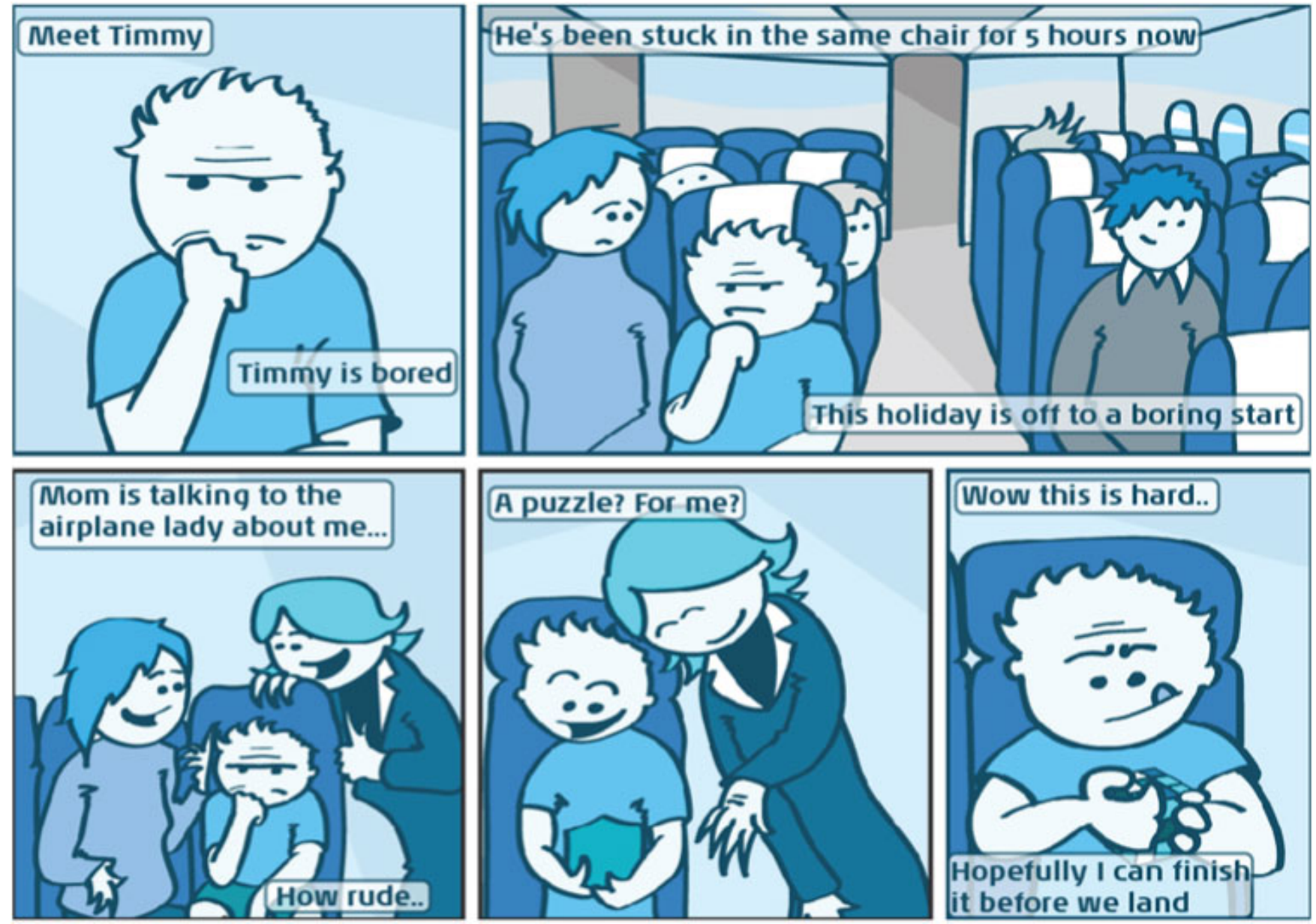

Figure 2. Scenario of handing out a gift in the Shareables service.

absorbed in their own world and unaware of their surroundings. For the crew this can be challenging, because it is difficult to see if such passengers would like to get some special attention, or even just a chat.

The questionnaire revealed that passengers appreciated personal attention from flight attendants, but not if they felt it was part of a routine or policy. This was especially true in case of problems, for instance, a noise problem or a space problem. Even though the available solutions were often very limited in the context of the airplane, passengers valued extra efforts that attendants did to help them with something. Secondly, passengers really liked small, free hand-outs, such as snacks or extra drinks. These also served as nice interruptions to the monotony of the flight experience. Overall, the lack of stimuli during the flight experience meant most passengers experienced low arousal emotions: calmness, boredom, placidity and sullenness.

The design phase focused on the low arousal of passengers and the opportunity to use small interactions to have a positive effect on people's mental states.

\section{Discussion}

In this design project, a service-system of gifts was created that aimed to provide specific passengers with small gifts that could positively impact their mental state. Although the idea for this system came from opportunities directly observed in the research, reversal theory helped to understand which gifts would be relevant and effective, and how they could be handed out to different passengers in different situations. Furthermore, reversal theory informed the setup of the focus group session and the questionnaire. In both methods the clarity of mental concepts helped respondents to express their emotions and motivations more sharply.

There were also parts of the theory where we felt more knowledge or details would help its application to design projects. First, although reversal theory emphasizes the dynamics of personality, it does include the concept of state dominance, and shows how, for example, people in different age groups tend to have different dominances (e.g., (Svebak and Murgatroyd, 1985). Because design processes often involve a focus on a specific target group, more knowledge 
about dominance would be helpful. Second, more information about the frequency and speed of reversals would be insightful. This would provide a better understanding of how often a product or service could or should attempt to trigger a reversal or a state change.

\section{References}

Apter, M. J. (2007). Reversal Theory: The Dynamics of Motivation, Emotion and Personality (2nd. ed). Oxford: Oneworld Publications.
Huijgen, R. (2014). Shareables: Designing an enhanced crew-passenger interaction for KLM. Unpublished Master's thesis. Delft (NL): Delft University of Technology.

Roozenburg, N.F.M., \& Eekels, J. (1995). Product Design, Fundamentals and Methods. Wiley, Chichester, UK.

Svebak, S., \& Murgotroyd, S. (1985). Metamotivatonal dominance: A multimethod validation of reversal theory construct. Journal of Personality and Social Psychology. 